\title{
Water Potential Model of Solar Grain Drying System with Vacuum Glass Hui SHEN ${ }^{a^{*}}$, Ji-Ping ZHOU ${ }^{b}$, Sheng-Yong YE \\ College of Mechanical Engineering, Yangzhou University, Yangzhou 225009, China \\ ahshen@yzu.edu.cn, bjpzhou@yzu.edu.cn, '88127952@qq.com \\ ${ }^{*}$ Corresponding author
}

\author{
Keywords: Grain Drying, Solar Energy Equipment, Quality Control, System Design, Moisture \\ Content.
}

\begin{abstract}
A solar grain drier with a sun drying system and vacuum glass was developed and the corresponding water potential model was established in this paper. It was shown from the simulation analysis of the grain drying process that the moisture content of grain could increase to14.0368\% with increasing the drying cycle from the first to the ninth. However, it decreased to $12.974 \%$ when the drying cycle was increased from the ninth to the twelfths. The optimum grain drying time was $2.57 \mathrm{hrs}$.
\end{abstract}

\section{Introduction}

Drying is one of the most important processes in agricultural production. Existing dryers normally use heater installation as drying energy. However, energy consumption is extremely large. The existing dry technology not only creates the grain internal stress but also increases the grain crack rates which can not guarantee high quality dried grain and reduces the economic efficiency of grain production greatly. Due to many problems existed in available dry technology, it is vital to hasten the development of solar energy and vacuum glass dry technology application. In particular, some small, simple solar drying chamber development should appear imminently. Grain usually requires low drying temperature, just matching the low temperature heat utilization in the field of solar energy. Therefore, it is necessary to apply solar energy into dry agricultural and subsidiary products. It has broad prospects for development [1].

Therefore, the purpose of this paper is to establish a numerical simulation system of grain drying process and reveal the change trend of the grain moisture content along with drying cycles.

\section{Design of Solar Energy and Vacuum Glass Grain Drying Equipment}

Solar Energy and Vacuum Glass Grain Drying Equipment is shown in Figure 1. The equipment was consisted of six parts: solar collector, grain drying warehouse, circulating water pump, control system, hot water tank, connection water pipes. Hot water flows from solar collector into heat exchanger under the section of water pump. Then hot water flows back into the tank after exchanged heat with the cold water in heat exchanger.

Grain drying warehouse model is shown in Figure 2. Grain flows from grain bucket into drying warehouse under the force of gravity, and flows along the surface of heat exchanger slowly, then discharge from grain outlet at the bottom of drying warehouse. A ventilation installation is at the bottom of drying warehouse. The cold wind blows through heat exchanger under the effect of installation, and then exchanges heat with hot water in heat exchanger. The heated hot air takes away moisture inside grain by grain layer. The hot air was exhausted from air outlet at the top of the drying warehouse after cross over three layers of heat exchanger. 


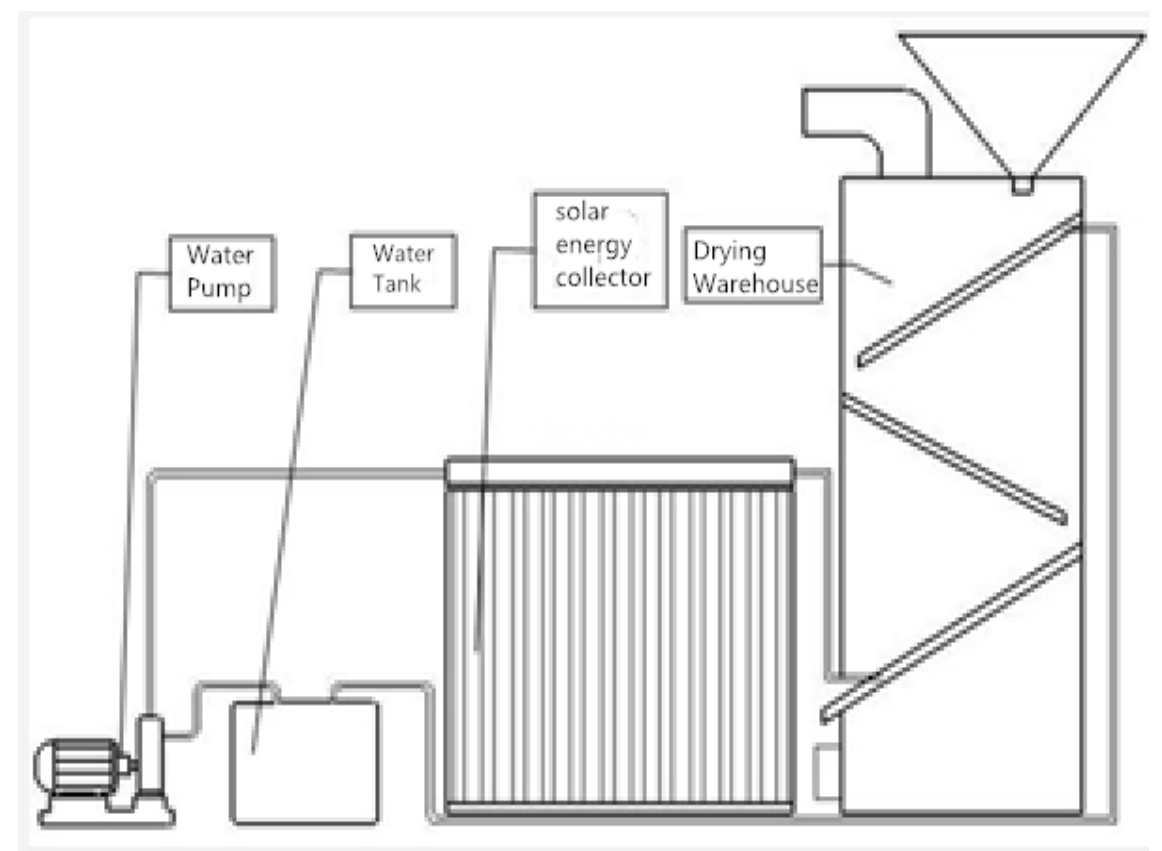

Fig.1 Solar Energy and Vacuum Glass Grain Drying Equipment

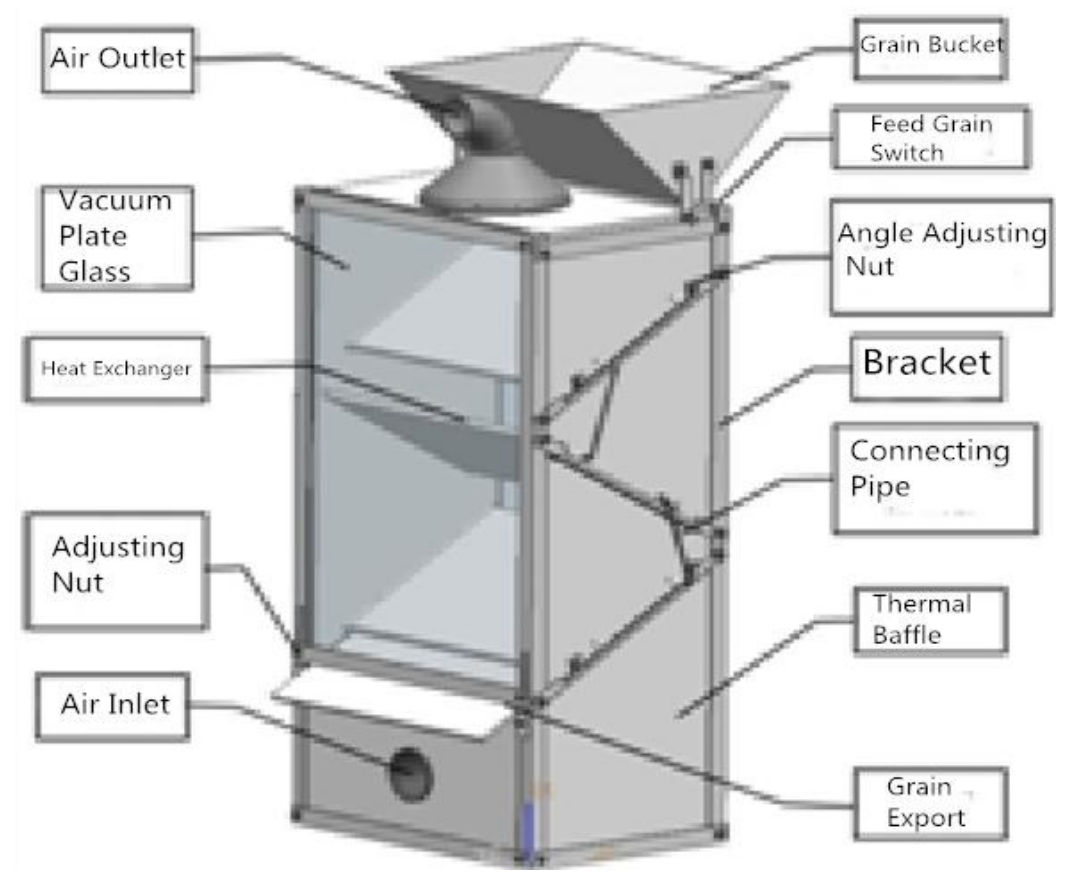

Fig.2 Grain Drying Warehouse Model

\section{Calculation of Grain Moisture}

The grain drying time relates to the evaporative efficiency of grain moisture content. The researching model of grain drying is equal to study grain moisture content flowing model[2]. We establish a model to find out the extent of grain drying along with time to calculate grain moisture content. That is, we use relative moisture content to indicate whether the grain was dried properly: [3],[4]

$$
M R=\frac{M(t)-M_{\mathrm{e}}}{M_{0}-M_{e}}
$$

In the formula: MR--the relative moisture content; $\mathrm{M}(\mathrm{t})$-- moisture content of grain at $\mathrm{t}$ time, \%; M0-- grain moisture content at the initial time, \%; Me-- grain moisture content in drying balance 
moment, \%. MR changes along with drying time. The calculation errors of the thin layer drying formula proposed by Page is smaller. The formula of Page's model is as follows:

$$
M R=\exp \left(-\mathrm{kt}^{\mathrm{c}}\right)
$$

In the formula $\mathrm{k}, \mathrm{c}$ are the drying constants. They were decided by temperature of drying hot air, relative humidity and the types of grain. The expressions of $\mathrm{k}, \mathrm{c}$ are as follows:

$$
\begin{aligned}
& k=0.01579+0.0001746 T-0.01413 R H \\
& c=0.6545+0.002425 T+0.078867 R H
\end{aligned}
$$

In the formula: $\mathrm{T}-$ - temperature of drying hot air, ${ }^{\circ} \mathrm{C}$; $\mathrm{RH}--$ relative humidity of hot air.

We can solve MR of t time by formula 2 and 3.We need to know M0 and Me, so that we can get $\mathrm{M}(\mathrm{t})$ by formula 1 . For the balance of grain drying moisture, we use the modified Henderson equation to calculate the variation of grain moisture. Specific expressions are as follows[3]:

$$
M_{e}=\left[\frac{-\ln (1-R H)}{a_{1}\left(T+a_{2}\right)}\right]^{1 / a_{3}}
$$

In the formula: Me--equilibrium moisture content of grain, \%; RH-- relative humidity of hot air; T-- temperature of dry hot air, ${ }^{\circ} \mathrm{C} ; \mathrm{a} 1, \mathrm{a} 2, \mathrm{a} 3$--Coefficients of equation coefficients. For rice, they were respectively chose $1.9187 \times 10-5,51.16,2.4451$.

Three pieces of heat exchange bed divide grain layer into three layers in the drying warehouse. We regard grain which on the low level of heat change bed as 1st, grain which on the middle level of heat change bed as 2nd,and grain which on the top level heat change bed as 3rd.Because the cold air has been heated by three layers of heat exchange bed, so the air temperature is different in each layer. Moreover the air humidity through the first layer is the same as the air humidity entering the second layer. The air humidity through the second layer is the same as the air humidity entering the third layer. So the air humidity through each layer is different, we need to calculate equilibrium moisture content of each layer. The $1 \mathrm{st}, 2 \mathrm{nd}$, the $3 \mathrm{rd}$ grain equilibrium moisture respectively is $M_{e n}^{\prime}$, $M_{e n}^{\prime \prime}, M_{e n}^{\prime \prime \prime}$. The air relative humidity through the layer 1 and layer 2 and layer 3 respectively is $R H_{n}^{\prime}$, $R H_{n}^{\prime \prime}, R H_{n}^{\prime \prime \prime}$.The air relative humidity increment through the layer 1 and layer 2 and layer 3 respectively is $\Delta R H_{n}^{\prime}, \Delta R H_{n}^{\prime \prime}, \Delta R H_{n}^{\prime \prime \prime}$. Namely:

$$
\begin{aligned}
& R H_{n}^{\prime \prime}=R H_{n}^{\prime}+\Delta R H_{n}^{\prime} \\
& R H_{n}^{\prime \prime \prime}=R H_{n}^{\prime}+\Delta R H_{n}^{\prime}+\Delta R H_{n}^{\prime \prime}
\end{aligned}
$$

Grain moisture evaporates into the air and then forms air relative humidity increment. We can get it by calculating the reduced amount of MR. Different drying temperature and air relative humidity, and even different drying cycle times at same grain layer would lead to different value of MR. The 1st, 2nd, the 3rd relative moisture content of grain respectively are $M R_{n}^{\prime}, M R_{n}^{\prime \prime}, M R_{n}^{\prime \prime \prime}$.After drying time of $\mathrm{t}$, the moisture content respectively is $M(t)_{n}^{\prime}, M(t)_{n}^{\prime \prime}, M(t)_{n}^{\prime \prime \prime}$.

Relative air humidity refers to the ratio of vapour pressure in the air to saturated vapour pressure. It also refers to the ratio of vapour mass in the air to vapours mass in the saturated air under the same temperature[5],that is:

$$
\Delta H R_{n}^{\prime}=\frac{M(t)_{n}^{\prime \prime}-M(t)_{n}^{\prime}}{R_{s}^{\prime}}
$$

$$
\Delta H R_{n}^{\prime \prime}=\frac{M(t)_{n}^{\prime \prime}-M(t)_{n}^{\prime \prime}}{R_{s}^{\prime \prime}}
$$

$$
\Delta H R_{n}^{\prime \prime \prime}=\frac{M(t)_{n-1}^{\prime}-M(t)_{n}^{\prime \prime \prime}}{R_{s}^{\prime \prime \prime}}
$$


In the formula $6, R_{s}^{\prime}, R_{s}^{\prime \prime}, R_{s}^{\prime \prime \prime}$ is vapour mass of saturated air which passed through $1 \mathrm{st}, 2 \mathrm{nd}$, 3rd layer. Its unit is $\mathrm{g} / \mathrm{kg}$. Due to different air temperature in each layer, vapour mass of saturated air is also different. Air temperature of the first layer is $45.5 \mathrm{oC}$, then $R_{s}^{\prime}=67 \mathrm{~g} / \mathrm{kg}$. Air temperature of the second layer is $55.9{ }^{\circ} \mathrm{C}$, then $R_{s}^{\prime \prime}=122 \mathrm{~g} / \mathrm{kg}$. The air temperature of the third layer is $60.6{ }^{\circ} \mathrm{C}$, then $R_{s}^{\prime \prime \prime}=155 \mathrm{~g} / \mathrm{kg}$.

We can get moisture content in each layer by formula 1.

$$
\begin{gathered}
M(t)_{n}^{\prime}=M R_{n}^{\prime}\left(M(t)_{n}^{\prime \prime}-M_{e}^{\prime}\right)+M_{e}^{\prime} \\
M(t)_{n}^{\prime \prime}=M R_{n}^{\prime \prime}\left(M(t)_{n}^{\prime \prime \prime}-M_{e}^{\prime \prime}\right)+M_{e}^{\prime \prime} \\
M(t)_{n}^{\prime \prime \prime}=M R_{n}^{\prime \prime \prime}\left(M(t)_{n-1}^{\prime}-M_{e}^{\prime \prime \prime}\right)+M_{e}^{\prime \prime \prime}
\end{gathered}
$$

Then we put formula 3 into formula 2 to calculate relative moisture content $M R_{n}^{\prime}, M R_{n}^{\prime \prime}, M R_{n}^{\prime \prime \prime}$ for grain at each layer after $\mathrm{N}$ times of drying cycles. In the formula, $\mathrm{t}$ is the time of drying cycle for single-layer. Its unit is min.

$$
\begin{gathered}
M R_{n}^{\prime}=\exp \left\{\left(-0.0237343+0.01413 R H_{n}^{\prime}\right) t^{0.7648375+0.078867 R H_{n}^{\prime}}\right] \\
M R_{n}^{\prime \prime}=\exp \left\{\left[-0.02555+0.01413\left(R H_{n}^{\prime}+\Delta R H_{n}^{\prime}\right)\right] t^{0.79-0.078867\left(R H_{n}^{\prime}+\Delta R H_{n}^{\prime}\right)}\right\} \\
M R_{n}^{\prime \prime \prime}=\exp \left\{\left[-0.026+0.01413\left(R H_{n}^{\prime}+\Delta R H_{n}^{\prime}+\Delta R H_{n}^{\prime \prime}\right)\right]^{0.8-0.078867\left(R H_{n}^{\prime}+\Delta R H_{n}^{\prime}+\Delta R H_{n}^{\prime \prime}\right)}\right\}
\end{gathered}
$$

Equilibrium water of each grain layer $M_{e n}^{\prime}, M_{e n}^{\prime \prime}, M_{e n}^{\prime \prime \prime}$ can be get when we put air temperature and humidity into formula 4.

$$
M_{e n}^{\prime}=\left[\frac{-\ln \left(1-R H_{n}^{\prime}\right)}{1.9187 \times 10^{-5}(45.5+51.16)}\right]^{1 / 2.451}
$$

$$
M_{e n}^{\prime \prime}=\left[\frac{-\ln \left(1-R H_{n}^{\prime}-\Delta R H_{n}^{\prime}\right)}{1.9187 \times 10^{-5}(55.9+51.16)}\right]^{1 / 2.451}
$$

$$
M_{e n}^{\prime \prime \prime}=\left[\frac{-\ln \left(1-R H_{n}^{\prime}-\Delta R H_{n}^{\prime}-\Delta R H_{n}^{\prime \prime}\right)}{1.9187 \times 10^{-5}(60.6+51.16)}\right]^{1 / 2.451}
$$

In the formula $7, M(t)_{n-1}^{\prime}$ is the moisture content of dried grain through the lowest heat exchange bed at the N-1th drying cycle. ${ }^{M R_{0}^{\prime}}$ of the first drying cycle is the initial relative moisture content of grain, $M R_{0}^{\prime}=23.1$ [6]. $R H_{n}^{\prime}$ in formula 5 and formula 8 is initial relative ventilation humidity. No matter how many times of the drying cycle, the value is always the air relative humidity, $R H_{n}^{\prime}=55 \%$. Accordingly, for the Nth cycle at t time in formula 6 to formula 9, there are $\Delta R H_{n}^{\prime}, \Delta R H_{n}^{\prime \prime}, \Delta R H_{n}^{\prime \prime \prime}$, $M R_{n}^{\prime}, M R_{n}^{\prime \prime}, M R_{n}^{\prime \prime \prime}, M_{e n}^{\prime}, M_{e n}^{\prime \prime}, M_{e n}^{\prime \prime \prime}, M(t)_{n}^{\prime}, M(t)_{n}^{\prime \prime}, M(t)_{n}^{\prime \prime \prime}$. There are 12 unknown quantities totally and we can solved it through 12 equations.

\section{Calculation of Drying Cycle Times}

The moisture in dried grain influences the satety of grain storage. China has its unified stipulation on safe storage of grain moisture [7]. Different grain types has different highest moisture content on the basis of different environment temperature. However, the moisture content of all kinds of grains should not exceed $14.5 \%$ [8] .In this paper, the grain drying device can realize recirculating drying. The cycle time for each turn is $4.3 \mathrm{~min}$. Grain moisture can be calculated after each time of drying according to formula (6) to formula (9). The moisture content is shown in Table. 
Tab.1 Drying Parameters

\begin{tabular}{ccccccc}
\hline $\mathbf{n}$ & $\Delta R H_{n}^{\prime}$ & $\Delta R H_{n}^{\prime \prime}$ & $\Delta R H_{n}^{\prime \prime \prime}$ & $M R_{n}^{\prime}$ & $M R_{n}^{\prime \prime}$ & $M R_{n}^{\prime \prime \prime}$ \\
\hline 1 & 0.0073 & 0.0051 & 0.0049 & 0.9494 & 0.9421 & 0.9342 \\
2 & 0.0061 & 0.0043 & 0.0041 & 0.9494 & 0.9420 & 0.9345 \\
3 & 0.0051 & 0.0036 & 0.0035 & 0.9494 & 0.9420 & 0.9347 \\
4 & 0.0042 & 0.0030 & 0.0029 & 0.9494 & 0.9420 & 0.9349 \\
5 & 0.0035 & 0.0025 & 0.0024 & 0.9494 & 0.9419 & 0.9350 \\
6 & 0.0028 & 0.0021 & 0.0021 & 0.9494 & 0.9419 & 0.9351 \\
7 & 0.0023 & 0.0018 & 0.0017 & 0.9494 & 0.9419 & 0.9352 \\
8 & 0.0019 & 0.0015 & 0.0015 & 0.9494 & 0.9419 & 0.9353 \\
9 & 0.0015 & 0.0013 & 0.0013 & 0.9494 & 0.9419 & 0.9354 \\
10 & 0.0012 & 0.0011 & 0.0011 & 0.9494 & 0.9419 & 0.9355 \\
11 & 0.0010 & 0.0009 & 0.0009 & 0.9494 & 0.9418 & 0.9355 \\
12 & 0.0008 & 0.0008 & 0.0008 & 0.9494 & 0.9418 & 0.9356 \\
\hline & $M_{e n}^{\prime}(\boldsymbol{\%})$ & $M_{e n}^{\prime \prime}(\boldsymbol{\%})$ & $M_{e n}^{\prime \prime}(\boldsymbol{\%})$ & $M(t)_{n}^{\prime}$ & $M(t)_{n}^{\prime \prime}(\boldsymbol{\%})$ & $M(t)_{n}^{\prime \prime}(\boldsymbol{\%})$ \\
\hline & & & & $(\boldsymbol{\%})$ & & \\
\hline 1 & 12 & 11.6247 & 11.5108 & 21.2258 & 21.7172 & 22.3376 \\
2 & 12 & 11.6083 & 11.5220 & 19.6613 & 20.0693 & 20.5899 \\
3 & 12 & 11.5945 & 11.4560 & 18.3503 & 18.6885 & 19.1254 \\
4 & 12 & 11.5830 & 11.4353 & 17.2535 & 17.5333 & 17.8999 \\
5 & 12 & 11.5734 & 11.4179 & 16.3355 & 16.5665 & 16.8742 \\
6 & 12 & 11.5653 & 11.4034 & 15.5671 & 15.7571 & 16.0156 \\
7 & 12 & 11.5586 & 11.3913 & 14.9237 & 15.0795 & 15.2967 \\
8 & 12 & 11.5530 & 11.3811 & 14.3850 & 14.5120 & 14.6946 \\
9 & 12 & 11.5482 & 11.3726 & 13.9338 & 14.0368 & 14.1904 \\
10 & 12 & 11.5443 & 11.3655 & 13.5559 & 13.6387 & 13.7680 \\
11 & 12 & 11.5410 & 11.3596 & 13.2393 & 13.3053 & 13.4143 \\
12 & 12 & 11.5382 & 11.3546 & 12.9741 & 13.0260 & 13.1178 \\
\hline
\end{tabular}

From Table 1 we can analyze the changes of water potential in the drying process. $M(t)_{n}^{\prime}$ is the moisture content of grains after one drying cycle. From the table, we can also find that the moisture content of grain reaches $14.0368 \%$ after nine times of drying cycle which can be satisfied with safety storage. The grain moisture content reduces along with increasing times of drying cycles. But reduction rate becomes more gradually with the increasing times of drying cycles. As is shown in Figure 3, the curvature of $M(t)_{n}^{\prime}, M(t)_{n}^{\prime \prime}, M(t)_{n}^{\prime \prime \prime}$ decreases gradually with the changes of drying cycles times. With increase of drying cycle times, drying air humidity increment in each layer also reduces gradually which can be seen in Figure 4. From Figure 4, we can also find that under the condition of same drying cycles, the increment of ventilate humidity through the first heat exchange bed is bigger than the second layer and the third layer.

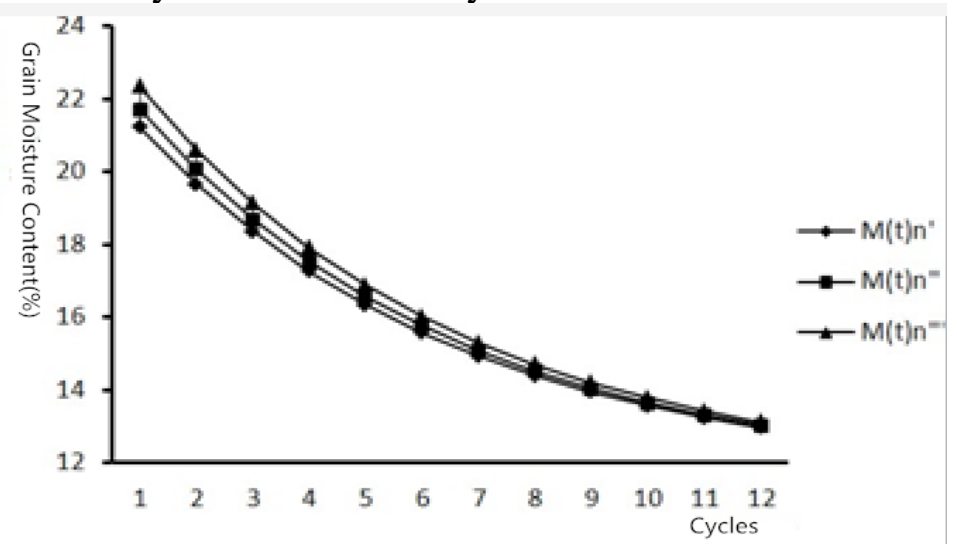

Fig.3 Changes of Moisture Content 


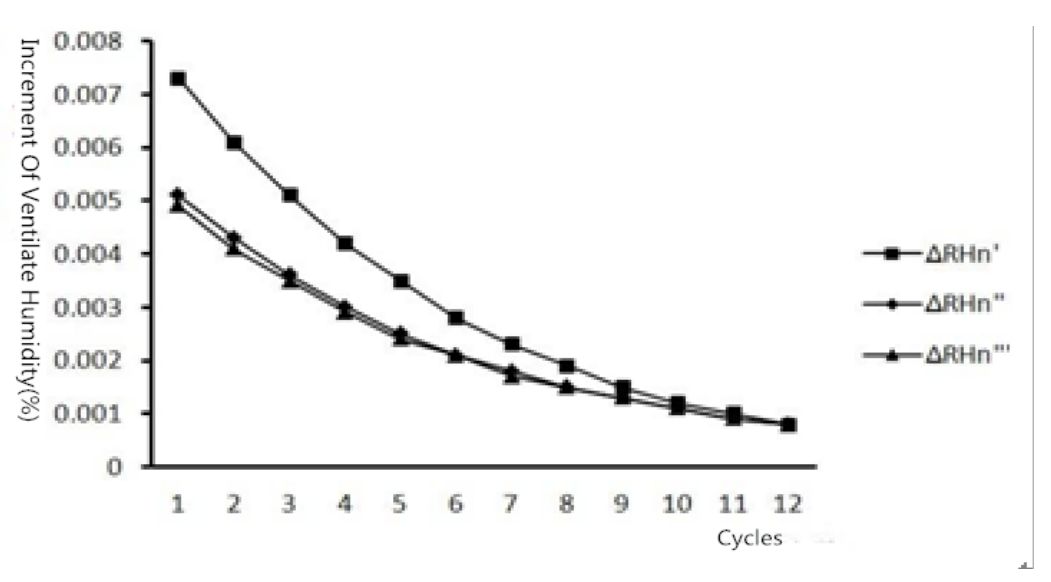

Fig.4 Increment Rate of Ventilation Function

According to above analysis, we can find that the moisture content of grain reaches $12.9741 \%$ after 12 drying cycle times. If cycle times continue to increase, the change of moisture content would be subtle and energy consuming would increase at the same time. Therefore, grain drying device designed in this paper chooses 12 drying cycle times.

\section{Conclusion}

A water potential model was developed for a solar grain drying system with vacuum glass. The result of numerical simulation demonstrated that the moisture content of grain firstly increased as high as $14.0368 \%$ after first nine drying cycles, and then dropped to $12.974 \%$ after increasing the drying cycle from the ninth to twelfths, and finally remained unchanged even after the farther prolongation of drying process time. The suggested optimum grain drying time was $2.57 \mathrm{hrs}$.

\section{References}

[1] Sagar V. R. . Suresh Kumar P. ,Recent advances in drying and dehydration of fruits and vegetables: a review , J Food SciTechnol (January-February 2010) 47(1):15-26.

[2] Zhe Liu, Zidan Wu,Xiaomeng Wang,Jia Song, and Wenfu Wu, Numerical Simulation and Experimental Study of Deep Bed Corn Drying Based on Water Potential, Mathematical Problems in Engineering, Volume 2015 (2015), Article ID 539846, 13 pages.

[3] Y. Sun, C. C. Pantelides, and Z. S. Chalabi, "Mathematical modelling and simulation of nearambient grain drying," Computers and Electronics in Agriculture, vol. 13, no. 3, pp. 243-271, 1995.

[4] D. Zare, S. Minaei, M. Mohamad Zadeh, and M. H. Khoshtaghaza, "Computer simulation of rough rice drying in a batch dryer," Energy Conversion \& Management, vol. 47, no. 18-19, pp. 3241-3254, 2006.

[5] Chongwen Cao. The principles and technologies of agricultural products drying[M]. Beijing: China Agricultural University Press, 2015, 369 386(in Chinese).

[6] Z. Yang, Y. J. Shao, J. L. Duan. Development of mechanization of grain drying in south China [J]. Agricultural Mechanization of China, 2012, 3:39 40(in Chinese).

[7] C. W. Cao, J. B. He. Developing trend of drying equipments of grains in overseas [J]. Modernized Agriculture, 2013, 1:40 43(in Chinese).

[8] C. Y. Li. Development of drying equipment of paddy grains in tropic region of south China [J]. Tropic Agricultural Engineering, 2012, 4:25 29(in Chinese). 